\title{
Effects of chemical dispersants on oil spill drift paths in the German Bight_-probabilistic assessment based on numerical ensemble simulations
}

\author{
Fabian Schwichtenberg ${ }^{1}$ - Ulrich Callies ${ }^{1} \cdot$ Nikolaus Groll $^{1} \cdot$ Silvia Maßmann $^{2}$
}

Received: 15 February 2016 / Accepted: 7 June 2016 / Published online: 21 June 2016

(C) The Author(s) 2016. This article is published with open access at Springerlink.com

\begin{abstract}
Oil dispersed in the water column remains sheltered from wind forcing, so that an altered drift path is a key consequence of using chemical dispersants. In this study, ensemble simulations were conducted based on 7 years of simulated atmospheric and marine conditions, evaluating 2,190 hypothetical spills from each of 636 cells of a regular grid covering the inner German Bight (SE North Sea). Each simulation compares two idealized setups assuming either undispersed or fully dispersed oil. Differences are summarized in a spatial map of probabilities that chemical dispersant applications would help prevent oil pollution from entering intertidal coastal areas of the Wadden Sea. High probabilities of success overlap strongly with coastal regions between $10 \mathrm{~m}$ and 20 $m$ water depth, where the use of chemical dispersants for oil spill response is a particularly contentious topic. The present study prepares the ground for a more detailed net environmental benefit analysis (NEBA) accounting also for toxic effects.
\end{abstract}

\section{Introduction}

The intertidal sand and mud flats of the Wadden Sea cover an area of about 4,700 $\mathrm{km}^{2}$ along the Dutch, German and Danish coasts (Reise et al. 2010). Their rich and biologically diverse

Responsible guest editor: C. Winter

Fabian Schwichtenberg

fabian.schwichtenberg@hzg.de

1 Institute of Coastal Research, Helmholtz-Zentrum Geesthacht, Max-Planck-Str. 1, 21502 Geesthacht, Germany

2 Bundesamt für Seeschifffahrt und Hydrographie, Bernhard-Nocht-Str. 78, 20359 Hamburg, Germany ecosystem is a migration stopover and wintering site for many birds (e.g. van Beusekom et al. 2012). Due to their proximity to busy shipping lanes, some of the Wadden Sea habitats are potentially endangered by nearshore oil spill incidents. Such an accident already happened in October 1998, when the cargo vessel PALLAS ran aground close to the island of Amrum (Reineking 1999). The subsequent oil spill affected about 12,000 sea birds residing in the North Frisian Wadden Sea (Fig. 1).

So far, contingency planning for the German North Sea coast considers only the use of mechanical devices because of concerns regarding toxic effects of chemical dispersants. Application of dispersants is regarded as a last resort response option (EMSA 2014). If mechanical cleaning is not promising, then dispersants could be applied without restriction in areas deeper than $20 \mathrm{~m}$, whereas it is strictly prohibited in areas shallower than $10 \mathrm{~m}$. At intermediate water depths (10-20 m), dispersants might potentially be used depending on the outcome of a case-specific assessment of environmental damages and benefits. With today's third-generation chemical dispersants being much less toxic (EMSA 2009), the option of using them particularly in inshore zones needs to be reassessed.

The advantages of using chemical dispersants are twofold: in the first place, dispersants reduce the pollutant volume on the water surface. In the second place, they facilitate biodegradation processes by increasing the reactive surface of the oil. However, their effectiveness much depends on the kind of oil spilled, its state of weathering (viscosity and degree of water in oil emulsions) and the hydraulic energy in the polluted area. Other factors of influence are salinity, turbidity and temperature (EMSA 2009).

Initially, concentrations of dispersed oil may be quite high before they get decreased by dilution and biological degradation. Even when toxicity of the dispersant itself is 
Fig. 1 Simulation of two hypothetical oil releases on 15 th March 2008 at high tide, based on the oil drift model PADM and PELETS-2D. Black ship symbols indicate locations of assumed accidents, dots dispersed oil, filled circles undispersed oil on surface, light blue intertidal areas of Wadden Sea. Particle locations calculated with PADM and PELETS-2D are colour coded in red and blue respectively. Centres of gravity of simulated particle clouds are indicated by white squares for PELETS and white triangles for PADM. Top panel Particle locations for scenario 1 after 5 days, four bottom panels particle locations for scenario 2 after 1 to 5 days

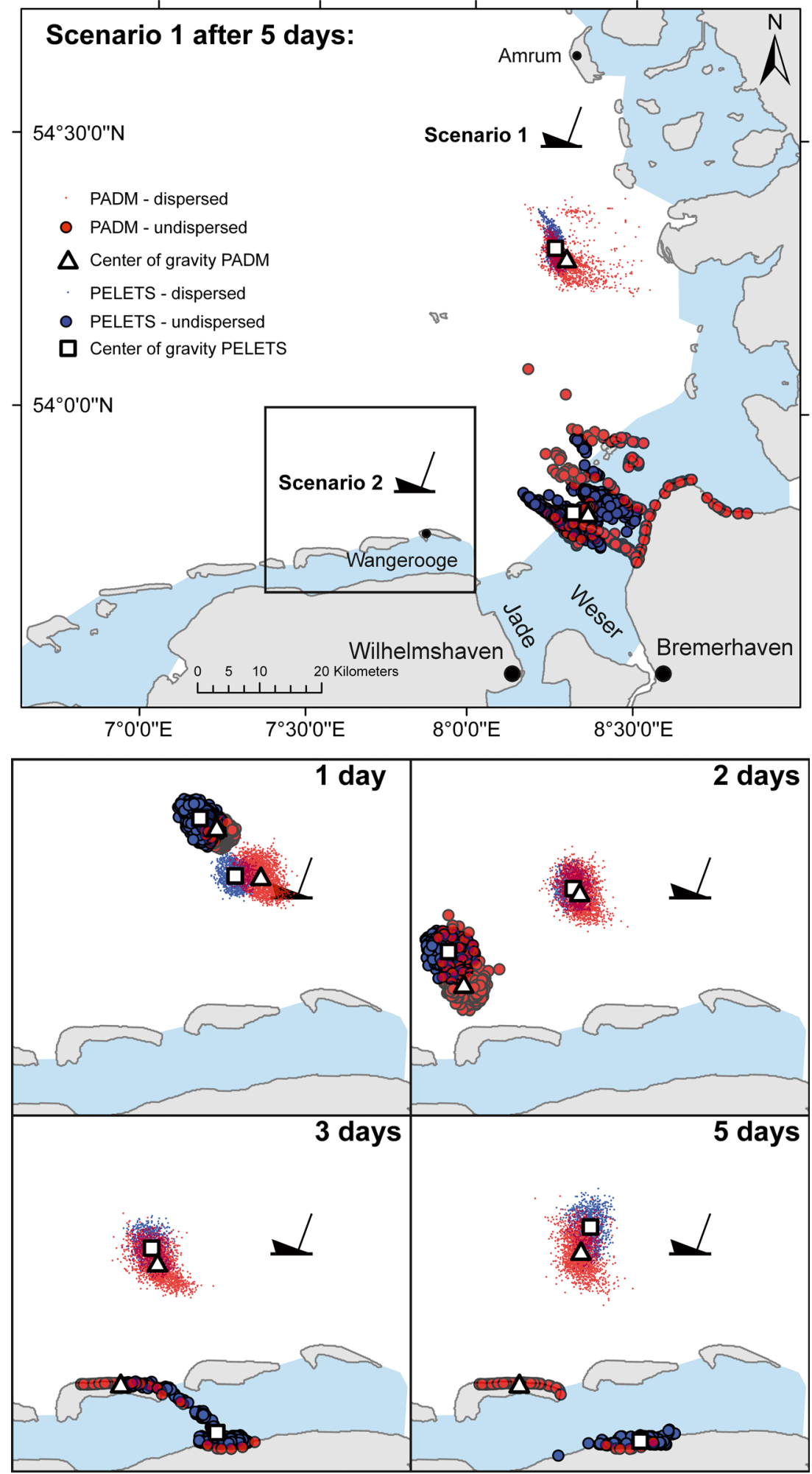

low, its application would increase the dissolution of toxic oil components in the sea. Therefore, the application of dispersants may be inappropriate in the vicinity of sensitive habitats if concentrations are expected to stay high long enough for toxic effects. Some sub-lethal effects from an exposure of fish to dispersed oil were observed in the DISCOBIOL research program (Le Floch et al. 2014). Toxic effects become less likely when dispersants are applied in deep water with sufficiently high mixing rates (EMSA 2009; Lee et al. 2011). 
French-McCay and Graham (2014) concluded that using dispersants may generate a net environmental benefit if the region within which water column biota would be exposed to dispersed oil is smaller than the region within which wildlife would be exposed to oil floating on the surface. However, for the German North Sea coast and Wadden Sea, decision making should also consider that in shallow intertidal areas interactions of dispersed oil with the sediment could be particularly relevant. Several biological habitats and communities are highly sensitive to untreated oil slicks, including mussel beds, shell mounds, sea grass meadows, salt marshes and stocks of resting and moulting birds. During 1 to 2 months in summer moulting birds are just swimming or drifting on the water, unable to fly. During this time they are much more vulnerable to untreated oil slicks than to chemically dispersed oil. Stock sizes and population dynamics are well known and monitored in the region (e.g. Koffijberg et al. 2003; Garthe et al. 2012). In some areas, stocks can reach far more than 100,000 individuals.

One aspect that often attracts less attention than it deserves is the simple fact that an oil slick's drift path would be altered by the application of chemical dispersants (API 1999). Oil dispersed in the water column remains sheltered from extra wind forcing as the most important driver for oil slicks drifting on the surface. Such changes of drift paths may prevent sensitive areas from being polluted, depending on prevailing wind and marine transport conditions. The present study focuses on this purely physical effect. Based on large ensemble simulations, chances of a successful reduction of pollution in sensitive areas were quantified probabilistically as a function of the location where an accident takes place. The criterion "successful" is defined as a reduction of at least $95 \%$ of oil entering sensitive areas. To enable a realistic representation of a large variety of different meteo-marine conditions, the simulations were initiated every $28 \mathrm{~h}$ within the 7 year period 2008-2014. The study postpones the dispersant-specific question of how effectively a particular oil type would be dispersed in a given environment. Of course, that is not to say that decision making in real hazardous situations would not require the inclusion of case-specific information regarding various aspects of the specific problem concerned.

The study is part of a German scientific project carried out by an interdisciplinary research consortium addressing various European and German regulations to assess the state of the marine environment in the German Bight, SE North Sea (for overviews, see Winter et al. 2014; Winter et al., Introduction article for this special issue). Until now, the capability of dispersants to protect coastal areas along the German part of the Wadden Sea is unknown, especially in the case of inshore oil spills. Therefore, the purpose of this work is to delineate the maximum range of drift path changes brought about by chemical dispersants simply by decreasing wind forcing. This information provides a key ingredient for a follow-up net environmental benefit analysis (NEBA) focusing on the ecological consequences of dispersant use.

\section{Methods}

The study analyses ensembles of hypothetical oil releases from 636 cells of a regular grid with about $5 \mathrm{~km}$ resolution. Disregarding the initial spreading phase, 2,190 hypothetical oil spills (every $28 \mathrm{~h}$ in the years 2008-2014) were initiated from each grid cell. For all accidents, 7 day drift paths were calculated both with and without the assumed application of chemical dispersants. In each of these about $2 \times 1.4$ million simulations, 1,000 tracer particles represent either pure oil or an oil-dispersant mixture.

Ensembles of simulations started according to a regular time schedule represent both frequencies and successions of different weather conditions in a realistic way. In this study, oil drifts are calculated using the offline Lagrangian transport toolbox PELETS-2D (Program for the Evaluation of Lagrangian Ensemble Transport Simulations, Callies et al. 2011), designed for conducting and evaluating comprehensive ensemble simulations based on 2D hydrodynamic fields. Marine currents were specified based on the 3D operational circulation model BSHcmod of the Federal Maritime and Hydrographic Agency (BSH) with $900 \mathrm{~m}$ resolution in the German Bight (Dick et al. 2001). BSHcmod is forced by winds from the regional model COSMO-EU (Consortium for Small-Scale Modelling) of the German Meteorological Service (DWD) with a spatial resolution of about $7 \mathrm{~km}$ over Europe. Both atmospheric and marine fields are available on a 15 minute basis. For drifting oil slicks, currents from the top layer of BSHcmod were selected, plus an extra wind drift parameterized as 0.018 times the wind velocity in $10 \mathrm{~m}$ height (Huber et al. 1987). By contrast, oil-dispersant mixtures submerged into the water column were assumed to be transported with vertically averaged BSHcmod currents. All particle trajectories were calculated including the effects of random movements due to subscale turbulence effects.

Using a 2D approach obviously means a substantial simplification. Further simplifications stem from the complete neglect of any oil weathering processes. Implications of these assumptions were exemplified by comparing results of the simplified approach used in this study with corresponding detailed simulations based on the fully fledged Lagrangian transport model PADM (PArticle Dispersion Model). PADM is the numerical core of the drift forecasting and backtracking system SeatrackWeb (STW; Ambjörn et al. 2013; Maßmann et al. 2014) operated by the BSH to provide advice to the Central Command for Maritime Emergencies Germany (CCME, Havariekommando). PADM is forced by full 3D current fields from BSHcmod and accounts for all relevant weathering processes. To mimic the influence of $100 \%$ effective chemical dispersants evaluated in this study, the 
algorithm for natural oil dispersion in PADM was modified assuming that at each time step $100 \%$ of surfaced oil becomes dispersed, regardless of its viscosity.

For each element of the ensemble of simulations (both with and without the assumed use of dispersants), the percentage of the released pollutant that crossed sensitive tidal flats (blue areas in Fig. 2) was evaluated at hourly time steps for the 7 day drift period. Additionally, times until the first $10 \%$ of oil polluting tidal flats arrived were monitored. Given the large ensemble of pair-wise simulations with and without dispersant application, only those hypothetical releases were counted as being successfully combated using chemical dispersants that fulfil two conditions:

1. Mean significant wave heights prevailing at the respective release position were within the range of $0.5-3.0 \mathrm{~m}$ during the first $6 \mathrm{~h}$ after the assumed accident.

2. The application of dispersants decreased the amount of oil entering sensitive areas by at least $95 \%$.

The first condition refers to Allen (1988, cited in Fingas 2004), who specified wave heights between about 0.5 and $3 \mathrm{~m}$ as a prerequisite for successful dispersant application. Although chemical dispersion needs a certain level of wave energy for mixing, the application of dispersants is unnecessary and ineffective if the wave energy is high enough for sufficient natural dispersion. The ocean wave information was taken from hindcast simulations (Groll and Weisse 2016) for the North Sea within the framework of coastDat (Weisse et al. 2015). The underlying model was version 4.5 .4 of the third-generation spectral wave model WAM (WAMDI-Group 1988). The model calculated directional wave spectra on a $0.050 \times 0.075^{\circ}$ latitude-longitude grid (approx. $3 \times 3 \mathrm{NM}$ ) with 35 frequencies and 24 directions. Wave parameters, such as the significant wave height, were stored on an hourly basis. At the lateral boundaries, wave spectra from a North Atlantic simulation were used to take into account wave fields generated outside the North Sea. Wind forcing for the wave data originated from a regional atmosphere hindcast simulation using the NCEP/NCAR reanalysis (Kistler et al. 2001) with a spectral nudging scheme (Geyer 2014).

The second of the above conditions seems to be very restrictive, but it must be seen in the context of the assumption of a $100 \%$ effective dispersant. If efficacies depending on oil type, weathering processes and environmental conditions were taken into account, then the threshold of pollution reduction would probably have to be adjusted differently.
Fig. 2 Probabilities that application of a $100 \%$ effective chemical dispersant would prevent at least $95 \%$ of the released oil from entering sensitive areas (blue), considering a maximum drift time of 7 days. Lines are the $10 \mathrm{~m}$ (grey) and 20 m (blue) depth contours

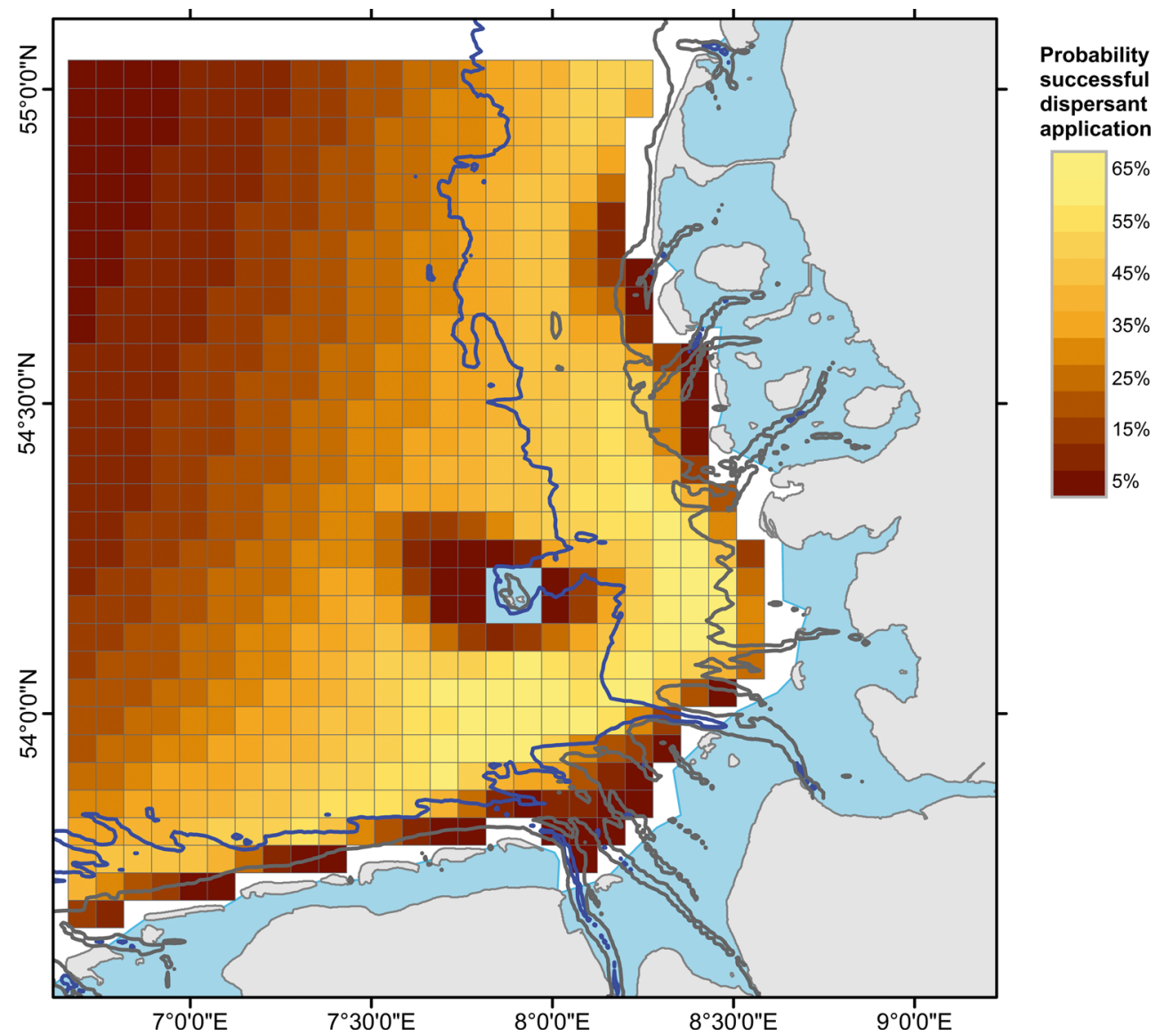




\section{Results}

\section{D versus 3D modelling}

Two example scenarios consider hypothetical oil releases at two different locations to contrast the simplified 2D model setup with detailed 3D simulations. In both cases, accidents are assumed to have taken place on 15 May 2008. Within the 5 subsequent days, very different meteorological conditions occurred with wind speeds ranging from about $5 \mathrm{~m} / \mathrm{s}$ on the first day to about 17 $\mathrm{m} / \mathrm{s}$ on the third day, when the wind turned from southeast to northwest. The first scenario assumes an accident in shallow water (depth about $8 \mathrm{~m}$ ) at $8.27^{\circ} \mathrm{E}, 54.53^{\circ} \mathrm{N}$ about $10 \mathrm{~km}$ to the southwest of the island of Amrum, close to where the PALLAS ran aground in October 1998 (Reineking 1999). The second scenario is at $7.83^{\circ} \mathrm{E}$, $53.90^{\circ} \mathrm{N}$ (water depth about $20 \mathrm{~m}$ ), $12 \mathrm{~km}$ to the north of the island of Wangerooge (roadstead "Neue Weser Nord") where ships anchor before they enter the ports of Wilhelmshaven or Bremerhaven.

Detailed 3D PADM scenario simulations are contrasted with simplified PELETS-2D simulations, the latter based on vertically averaged values of the same currents also fed into PADM. In PADM, simulations refer to heavy fuel oil. If oil is assumed to be $100 \%$ chemically dispersed, then the selected oil type matters neither in PADM nor in PELETS-2D. For untreated oil, however, the oil type impacts drift behaviour in PADM via changing strengths of physical vertical dispersion.

For both scenarios, Fig. 1 shows the final situation after 5 days. Intermediate states after 1, 2 and 3 days are shown only for the second scenario. In both scenarios the untreated oil reaches the Wadden Sea, in scenario 1 after having travelled about $80 \mathrm{~km}$ to the south. Regardless of the model used, application of a dispersant considerably slows down particle drifts so that the oil/dispersant mixture remains outside the tidal basins. After 5 days, distances between the centres of gravity of particle clouds simulated with PADM and PELETS range between 3 and $4 \mathrm{~km}$ respectively. An exception is undispersed oil in scenario 2 because, in this case, the majority of the particles in PADM already beach at the northern shoreline of a barrier island. Beaching is neglected in PELETS, so that tracer particles may "slide" along the barrier island's coast, making it more likely that they enter the Wadden Sea.

\section{Ensemble simulations}

The key result of this study (Fig. 2) is a probability map based on 2,190 hypothetical oil spill events assumed to have occurred within each of 636 different cells of a regular grid covering the inner part of the German Bight. The map shows the spatial distribution of the chances that application of a $100 \%$ effective chemical dispersant immediately after an oil spill occurred would successfully prevent pollution from entering sensitive areas (shaded in blue).

High success rates can be found in regions that are at least 5-10 km away from sensitive areas. The maximum distance that makes effects of dispersion dispensable depends on the orientation of the coast relative to the main wind directions. Along the south-north oriented part of the German coast, the regions of high probabilities that applications of dispersants would be successful in the sense of this study (successful=oil does not enter sensitive areas) overlap with regions with water depths between $10 \mathrm{~m}$ and $20 \mathrm{~m}$, where the application of dispersants is officially restricted by the outcome of a caseby-case assessment.

In any oil-combating measures, time plays an important role. If oil slicks reach sensitive areas within, say, a few hours, then there may not be enough time for organizing the application of dispersants. On the other hand, if dispersed oil does not reach any sensitive areas within $72 \mathrm{~h}$, then it will usually be sufficiently diluted to avoid substantial harm to the ecosystem. Figure 3 shows 10 th percentiles of travel time for untreated oil on the surface and dispersed oil in the water column. Generally, travel times increase with the distance from sensitive areas. The maximum drift time taken into account equals the length of drift trajectories (7 days) calculated. Percentiles refer to the total amount of oil that enters any sensitive area within 7 days. Percentiles remain undefined for grid cells from which no pollution arises, a situation that occurs only for dispersed oil sheltered from wind drift.

\section{Discussion}

The example described above shows that, although simplified PELETS-2D simulations differ from full 3D simulations with PADM, the changes of drift behaviour brought about by (100\% effective) chemical dispersion are clearly not masked by, and do not crucially depend upon, the simplifying assumptions made. In this context, it should also be kept in mind that empirical data for model validation are lacking.

Detailed numerical drift and fate simulations are nowadays state-of-the-art tools for predicting the evolution of an oil spill incident (see, for example, Broström et al. 2013). Most of the uncertainty involved resides in the intensities of oil weathering processes under specific atmospheric/marine conditions. Relatively simple parameterizations are employed to approximate spatially averaged effects of complex processes on scales unresolved by the model. But even when the oil weathering model can be considered quasi-perfect, information about how any specific oil would behave in contact with a specific dispersant is often very sketchy. In this study, the 


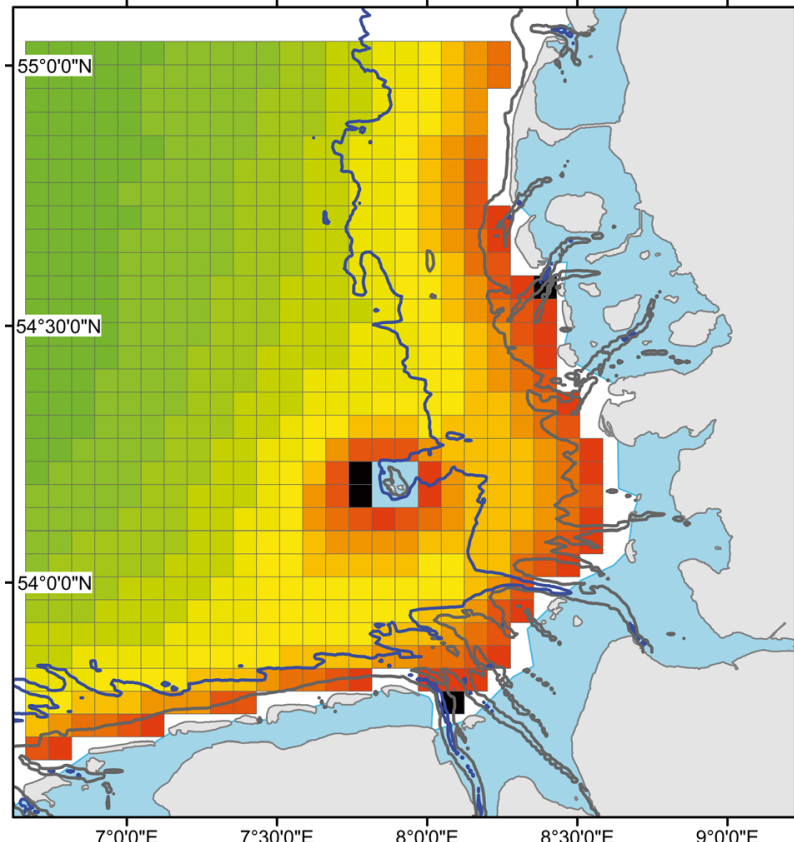

Fig. 3 Spatial distribution of the 10th percentiles of travel times of untreated (left) and dispersed (right) oil entering sensitive areas (blue). The $10 \mathrm{~m}$ and $20 \mathrm{~m}$ depth contours are marked in grey and dark blue

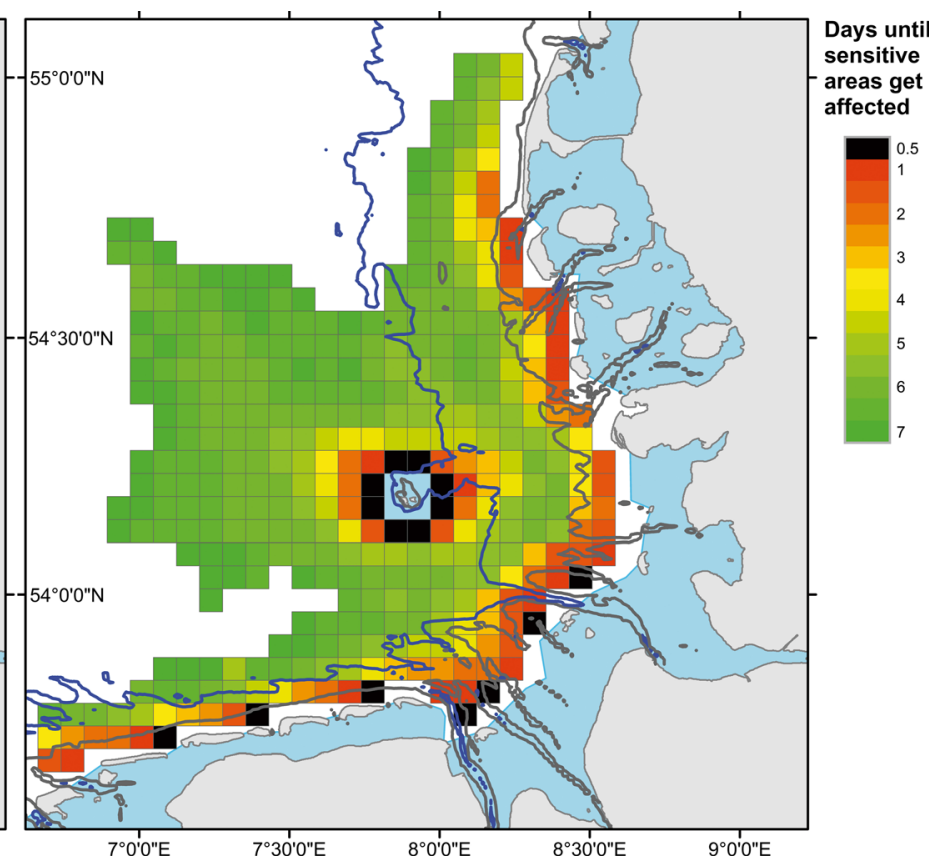

respectively. Grid cells from which no dispersed oil enters any sensitive area are faded out focus on pure drift behaviour avoided the inclusion of too many details that would have complicated the broad picture.

Long-term model-based reconstructions of environmental conditions (e.g. Weisse et al. 2009) are nowadays available and provide a realistic picture of natural variability. In the context of risk assessments, such datasets are of great value in that they implicitly represent the correct statistics of weather conditions (e.g. Chrastansky and Callies 2009). In this study several years of archived output from operational BSH simulations were used, relieving the analyst from the need to prespecify and properly weight a number of fixed reference weather situations. Wind and current data were supplemented by wave data generated for climate study applications.

It is important to realize that numerical values of the probabilities that application of a dispersant at given locations would improve the situation after a hypothetical accident occurred (Fig. 2) may have different interpretations. Generally, application of dispersants was labelled unsuccessful if significant wave heights were not in the required range of 0.5-3.0 $\mathrm{m}$. Wave energy being either too low or too high occurred for somewhat less than $25 \%$ of all simulated oil spill events, so that a success rate of about $75 \%$ could not be surpassed. This puts the upper limit $(65 \%)$ of the probability scale attached to Fig. 2 into perspective.

In addition, the use of dispersants was labelled unsuccessful in all cases when it did not improve the situation. This applies in particular to those accidents far from the coast that would not endanger sensitive tidal flats anyway (within 1 week's time). Applications of dispersants were labelled unsuccessful in the sense that they were needless. This also applies to inshore regions if barrier islands shelter tidal basins from being polluted.

Whether or not the use of dispersants at nearshore locations diminishes the amount of oil entering the intertidal zone depends on whether the wind drift suppressed by chemical dispersion would act in favour (offshore breezes) or to the disadvantage (onshore breezes) of coastal protection. Even for onshore breezes, however, chemical dispersion may be useless if the location of pollutant release is close enough so that the pollutant can enter sensitive areas following tidal transport. This depends on the tidal phase at which an accident occurs as well as on the orientation and size of the local tidal ellipse. Tidal ellipses in the German Bight were described by Carbajal and Pohlmann (2004), Port et al. (2011) and Stanev et al. (2015), for instance. When dispersed oil can enter the Wadden Sea via tidal currents, any positive effects of dispersion through changed drift paths disappear. This explains the broader belt of low success rates in the Jade-Weser region (east of $8^{\circ}$ east, Fig. 2).

One simplifying assumption in this study is that dispersants were applied immediately after an accident took place. In practice, dispersants would be applied as soon as possible to start the intended effect in a timely manner. Otherwise oil viscosities increasing with time could hamper the formation of small oil droplets. However, toxicity of dispersed oil may also be affected by weathering of oil prior to chemical dispersion. According to French-McCay and Payne (2001), especially evaporation of the most toxic oil components from a 
surface oil slick reduces the toxicity of dispersed oil. These constituents tend to evaporate already within the first hours after an oil spill incident, so that French-McCay and Payne (2001) found toxicities of oil-dispersant mixtures to be considerably higher if dispersants were used within the first $6 \mathrm{~h}$. For logistic reasons, however, an application of dispersants within the first few hours is difficult anyway.

Even if a pollutant cannot be prevented from reaching the coast, in most cases its arrival would be much delayed by a (perfect) dispersant's use (Fig. 3). As dispersed oil is no longer accessible for mechanical cleaning, the benefit would not be a gain of additional time for taking mechanical response measures but rather a better chance for dilution and microbiological degradation. Furthermore, the latter processes are also more active for oil-dispersant mixtures than for untreated oil slicks (Lee et al. 2011).

Some generalizations of this study are conceivable. Regarding the assumption of a $100 \%$ effective dispersant, results of the two alternative simulations with untreated and $100 \%$ chemically dispersed oil could be combined with weighting factors based on expert knowledge on the efficacy of the dispersant under given environmental conditions (temperature, salinity, wave energy). The definition of environmental harmfulness adopted in this study is very simple: an oil slick is assumed to produce substantial damages only if it enters a coastal basin. Switching to a concept based on water depth and its potential for dilution (cf. Le Floch et al. 2014) would be straightforward. For many practical applications, detailed maps of sensitive habitats or communities of endangered birds exist (e.g. Koffijberg et al. 2003; Garthe et al. 2012). This additional information must obviously be taken into account. Figure 2 of the present study, concentrating on modified drift behaviour, establishes a basis for performing such a fully fledged precautionary NEBA related to the application of chemical dispersants in German coastal areas.

\section{Conclusions}

In Germany the use of chemical dispersants for combating oil spills in coastal areas is understood only as a last resort. The discussion often focuses on aspects of technical applicability, efficacy and toxicity. However, another key criterion for decisions on the potential use of dispersants should be whether winds are expected to act in favour or to the disadvantage of coastal protection. The probabilistic map produced in the present study identifies areas where the chances that chemical dispersant application would keep a pollutant out of vulnerable tidal basins are particularly high. These areas were found to strongly overlap with nearshore regions between $10 \mathrm{~m}$ and $20 \mathrm{~m}$ water depth. A detailed site-specific NEBA particularly for such areas would be the logical next step to ensure that no negative side effects counteract expected benefits from modified drift behaviour. Comprehensive monitoring of seabed habitats and communities is obviously an indispensable prerequisite for that purpose.

While winds and currents are reliably represented by model-based reconstructions, the analysis in this study disregarded many aspects that are definitely highly relevant for practical decision making but depend on details of the specific accident that occurred. The type of oil spilled, for instance, determines both oil weathering and the efficacy of the dispersant applied. But even when such details are known in advance, values of process-related parameters in corresponding simulations would still be highly uncertain.

It is argued that for any real accident, already using two idealized simulations with either undispersed or fully dispersed oil provides a useful pragmatic approach to delineate the corridor of possible developments and regions possibly endangered. Doubts how to properly weight the two extreme cases reflect inevitable uncertainty with regard to the strength of weathering and dispersant efficacy. Pressed for time, expert experience and available evidence is needed to build a basis for reasonable decisions.

Acknowledgements The research was funded by the WIMO project supported by two ministries in Lower Saxony: the "Ministerium für Umwelt, Energie und Klimaschutz" as well as the "Ministerium für Wissenschaft und Kultur". We would like to thank Ulrike Kleeberg for help with GIS applications and Carlo van Bernem for constructive discussions. The article benefitted from constructive assessments by M.G. Hadfield and an anonymous reviewer.

\section{Compliance with ethical standards}

Conflict of interest The authors declare that there is no conflict of interest with third parties.

Open Access This article is distributed under the terms of the Creative Commons Attribution 4.0 International License (http:// creativecommons.org/licenses/by/4.0/), which permits unrestricted use, distribution, and reproduction in any medium, provided you give appropriate credit to the original author(s) and the source, provide a link to the Creative Commons license, and indicate if changes were made.

\section{References}

Allen AA (1988) Comparison of response options for offshore oil spills. In: Proc 11th Arctic and Marine Oil Spill Program Technical Seminar, Environment Canada, Ottawa, ON, p 289-306

Ambjörn C, Liungman O, Mattsson J, Hakansson B (2013) Seatrack Web: the HELCOM tool for oil spill prediction and identification of illegal polluters. In: Kostianoy AG, Lavrova OY (eds) Oil pollution in the Baltic Sea. Springer, Berlin, pp 155-184

API (1999) A decision maker's guide to dispersants. American Petroleum Institute, Publication no 4692

Broström G, Carrasco A, Hole LR, Dick S, Janssen F, Mattsson J, Berger S (2013) Usefulness of high resolution coastal models for operational oil spill forecast: the "Full City" accident. Ocean Sci 7(6):805-820 
Callies U, Plüß A, Kappenberg J, Kapitza H (2011) Particle tracking in the vicinity of Helgoland, North Sea: a model comparison. Ocean Dyn 61:2121-2139

Carbajal N, Pohlmann T (2004) Comparison between measured and calculated tidal ellipses in the German Bight. Ocean Dyn 54:520-530

Chrastansky A, Callies U (2009) Model-based long-term reconstruction of weather-driven variations in chronic oil pollution along the German North Sea coast. Mar Pollut Bull 58:967-975

Dick S, Kleine E, Müller-Navarra S (2001) The operational circulation model of BSH (BSHcmod) - Model description and validation. Berichte des Bundesamtes für Seeschifffahrt und Hydrographie, Hamburg, no 29

EMSA (2009) Manual on the applicability of oil spill dispersants. European Maritime Safety Agency, Lisbon

EMSA (2014) Inventory of national policies regarding the use of oil spill dispersants in the EU member states 2014. European Maritime Safety Agency, Lisbon

Fingas M (2004) Weather windows for oil spill countermeasures. Environmental Technology Centre, Environment Canada, for Prince William Sound Regional Citizens' Advisory Council. www.pwsrcac.org

French-McCay D, Graham E (2014) Quantifying tradeoffs - net environmental benefits of dispersant use. In: Proc Int Oil Spill Conf, May 2014, vol 2014, no 1, p 762-775

French-McCay DP, Payne JR (2001) Model of oil fate and water concentrations with and without application of dispersants. In: Proc 24th Arctic and Marine Oilspill (AMOP) Technical Seminar, Edmonton, Alberta, 12-14 June 2001, Environment Canada, p 611-645

Garthe S, Markones N, Mendel B, Sonntag N, Krause JC (2012) Protected areas for seabirds in German offshore waters: designation, retrospective consideration and current perspectives. Biol Conserv 156:126-135

Geyer B (2014) High-resolution atmospheric reconstruction for Europe 1948-2012: coastDat2. Earth System Sci Data 6:147-164. doi:10.5194/essd-6-147-2014

Groll N, Weisse R (2016) coastDat-2 North Sea wave hindcast for the period 1949-2014 performed with the wave model WAM. World Date Center for Climate (WDCC) at DKRZ. doi:10.1594/WDCC/coastDat-2 WAM-North Sea

Huber K, Püttger, Soetje KC (1987) Results on the prediction of the drift of oil spills during Archimedes 2 by means of a numerical model. In: Gillot RH (ed) The Archimedes 2 experiment. Commission of the European Communities, p 179-193

Kistler R, Kalnay E, Collins W, Saha S, White G, Wollen J, Chelliah M, Ebisuzaki W, Kanamitsu M, Kousky V, van den Dool H, Jenne R, Fioriono M (2001) The NCEP-NCAR 50-year reanalysis: monthly means CD-ROM and documentation. Bull Am Meteorol Soc 82: 247-268

Koffijberg K, Blew J, Eskildsen K, Günther K, Koks B, Laursen K, Rasmussen LM, Südbeck P, Potel P (2003) High tide roosts in the Wadden Sea: a review of bird distribution, protection regimes and potential sources of anthropogenic disturbance. Report Wadden Sea Plan Project 34. Wadden Sea Ecosystems no 16. Common Wadden Sea Secretariat, Trilateral Monitoring and Assessment Group, Wilhelmshaven, Germany

Lee K, Nedwed T, Prince RC (2011) Lab tests on the biodegradation rates of chemically dispersed oil must consider natural dilution. In: Proc Int Oil Spill Conf, March 2011, vol 2011, no 1, abs245

Le Floch S, Dussauze M, Merlin F-X, Claireaux G, Theron M, Le Maire P, Nicola-Kopee A (2014) DISCOBIOL: assessment of the impact of dispersant use for oil spill response in coastal or estuarine areas. In: Proc Int Oil Spill Conf, May 2014, vol 2014, no 1, p 491-503

Maßmann S, Janssen F, Brüning T, Kleine E, Komo H, MenzenhauerSchumacher I, Dick S (2014) An operational oil drift forecasting system for German coastal waters. Die Kueste 81:255-271

Port A, Gurgel KW, Staneva J, Schulz-Stellenfleth J, Stanev EV (2011) Tidal and wind-driven surface currents in the German Bight: HFR observations versus model simulations. Ocean Dyn 61:1567-1585

Reineking B (1999) The PALLAS accident. Wadden Sea Newslett 1999 $1: 22-25$

Reise K, Baptist M, Burbridge P, Dankers N, Fischer L, Flemming B, Oost AP, Smit C (2010) The Wadden Sea-a universally outstanding tidal wetland. Wadden Sea Ecosystem no 29. Common Wadden Sea Secretariat, Wilhelmshaven, Germany, p 7-24

Stanev EV, Ziemer F, Schulz-Stellenfleth J, Seemann J, Staneva J (2015) Blending surface currents from HF radar observations and numerical modeling: tidal hindcasts and forecasts. $\mathrm{J}$ Atmos Ocean Technol 32: 256-281

van Beusekom JEE, Buschbaum C, Reise K (2012) Wadden Sea tidal basins and the mediating role of the North Sea in ecological processes: scaling up of management? Ocean Coast Manage 68:69-78

WAMDI-Group (1988) The WAM model - a third generation ocean wave prediction model. J Phys Oceanogr 18:1776-1810

Weisse R, von Storch H, Callies U, Chrastansky A, Feser F, Grabemann I, Guenther H, Pluess A, Stoye T, Tellkamp J, Winterfeldt J, Woth K (2009) Regional meteo-marine reanalyses and climate change projections: results for Northern Europe and potentials for coastal and offshore applications. Bull Am Meteorol Soc 90(6):849-860

Weisse R, Bisling P, Gaslikova L, Geyer B, Groll N, Hortamani M, Matthias V, Maneke M, Meinke I, Meyer EMI, Schwichtenberg F, Stempinski F, Wiese F, Wöckner-Kluwe K (2015) Climate services for marine applications in Europe. Earth Perspectives 2:3. doi:10.1186/s40322-015-0029-0

Winter C, Herrling G, Bartholomä A, Capperucci R, Callies U, Heipke C, Schmidt A, Hillebrand H, Reimers C, Bremer P, Weiler R (2014) Scientific concepts for monitoring the ecological state of German coastal seas (in German). Wasser und Abfall 07-08(2014):21-26. doi:10.1365/s35152-014-0685-7 